Journal of Economic Geography, 2012, Volume 10, Number 4, Pages 599-618

\title{
The Shifting Geography of Competitive Advantage: \\ Clusters, Networks and Firms
}

\author{
MARK JENKINS* \\ Cranfield School of Management \\ Cranfield \\ Bedfordshire \\ MK43 0AL \\ United Kingdom \\ mark.jenkins@cranfield.ac.uk \\ Tel: +44 (0) 1234754407 \\ Fax: $+44(0) 1234751806$ \\ STEPHEN TALLMAN \\ University of Richmond \\ Richmond \\ VA 23173 \\ USA \\ stallman@richmond.edu \\ Tel: +1 804/ 287-6589
}

* Point of contact for Editors.

Paper accepted for the Special Issue of the Journal of Economic Geography:

"International Business and Economic Geography: The Multinational in Geographical

Space" 


\title{
The Shifting Geography of Competitive Advantage: \\ Clusters, Networks and Firms
}

\begin{abstract}
$\underline{\text { Abstract }}$
We consider the dynamics of knowledge-based sources of advantage as they move between geographical locations and multinational and other firm level networks using the specialist context of Formula 1 motor over a fifty nine year period. We suggest that shifts in competitive advantage are underpinned by the movement of both architectural and component knowledge at both the firm and cluster level, and in particular we suggest that isolated firms can both benefit from and add to cluster level knowledge. We conclude by suggesting ways in which MNEs can adapt their approach to both location and knowledge development in order to enhance their ability to create competitive advantage.
\end{abstract}

Keywords

Clusters, competitive advantage, networks, knowledge flows, Formula 1. 


\section{Introduction}

An important development in the study of multinational firms and knowledge-based competitive advantage in recent years is the recognition that unique, rent-generating knowledge can be found in many locations around the globe. No longer are multinational firms assumed to be interested in foreign locations only as potential markets for goods and services embodying knowledge developed in the home country; rather, they are explicitly found to use these locations as sources of innovative knowledge (Tallman and FladmoeLindquist, 2002). If such knowledge can be absorbed by the multinational through a local subsidiary or joint venture operation and then transmitted to the rest of the firm for combination with knowledge from yet other locations (Gupta and Govindarajan, 2000), the multinational firm can create the kind of idiosyncratic firm-specific capabilities that generate sustained competitive advantage (Mudambi and Navarra, 2004). Further, this specialized knowledge is no longer seen as widely available throughout host nations, but rather as concentrated in specialized city-regions, industrial districts, or geographical clusters (Porter, 1998).

This study uses the concepts of architectural and component knowledge (Matusik and Hill, 1998; Tallman, Jenkins, Henry and Pinch, 2004) to examine the movement of knowledge within and between firms in such geographical industry clusters in order to improve our understanding of how multinational firms can access, internalize, and reconfigure sticky, location-tied knowledge into unique firm-specific capabilities. Previous work has suggested that clusters or proximate networks of firms can offer sources of sustained competitive advantage to the firms (including the subsidiaries of multinational firms) residing within them (Porter, 1998; Pinch, Henry, Jenkins and Tallman, 2003). In this study we consider further the dynamics of knowledge based sources of competitive advantage both among firms within geographical clusters and between firms and groups of firms in different 
locations. To do so, we focus on the technological innovations and the relative competitive advantage of clusters and cluster-based firms using the specialized context of Formula 1 (F1) motor racing over a fifty-nine year period between 1950 and 2008. We use a guided inductive approach by considering a series of propositions to interrogate longitudinal case study data. We observe both the emergence and transitions over time of clusters and of firm-level intercluster networks and are able to consider how such shifts enable the creation of new forms of knowledge which lead to competitive advantage.

\section{The Geography of Knowledge and Competitive Advantage}

The concept that regionally-tied advantage might arise from a combination of unique knowledge assets is the basis for a variety of models of industrial districts or clusters in economic geography (Saxenian, 1994; Maskell 2001) and strategic management (Porter, 1998; Tallman et al, 2004). While the application of cluster concepts to technology-intensive industries is evolving, most models assume that core knowledge is sticky - tightly bound to its originating location - leading to sustainable competitive advantage for firms within a cluster (Lawson, 1997). Other work proposes that isomorphic pressures will lead to knowledge convergence among the firms in a region leading to a tendency for the focus of innovation to narrow over time, thereby resulting in a move away from more radical breakthrough innovations (Damanpour, 1991). Location-based determinism for the knowledge attributed to a particular region makes change appear to be at best difficult and at worst impossible, such that embedded regional sources of advantage become sources of disadvantage over time as the regions, and likewise the firms within them, are unable to respond to change (Pouder and St. John, 1996).

We propose, though, that the knowledge base in any cluster can evolve through innovation, rather than stagnate or lose value through inter-regional imitation. One way in which the capabilities found in clusters evolve is through spillovers and re-combination of 
ideas to stimulate development among firms within the regional cluster. Another possibility is the migration of knowledge from one location to others, often through active intervention by multinational firms. While differences in knowledge stocks may act as isolating mechanisms to slow knowledge flows between regions (Pinch et al., 2003), these geographical clusters of companies are not, in fact, completely isolated, and knowledge flows between regions within an industry play key roles in the evolution of industry knowledge stocks and the shift over time of competitive advantage.

\subsection{Defining Knowledge Types}

Tallman et al. (2004) consider knowledge development at both the firm and the cluster level using the notion of component and architectural knowledge (Henderson and Clark, 1990; Matusik and Hill, 1998). They propose that these two distinctive types of knowledge have both firm-specific and cluster-specific effects. Architectural knowledge in particular is seen to be highly path-dependent and immobile, and therefore limited in flow across firm or cluster boundaries (Tallman et al., 2004). Component knowledge flows are enhanced within a firm or cluster by common cluster-level architectural knowledge, while different - often competing sets of architectural knowledge between organizations or clusters act as isolating mechanisms to slow the movement of component knowledge across boundaries (Pinch et al., 2003).

Component knowledge consists of those specific knowledge resources, skills, and technologies that relate to the component parts of an organizational system rather than to the whole (Tallman et al., 2004). Component knowledge is tied normally to the technology of the industry and is relatively coherent and definable rather than personal or historical, and therefore is potentially transferable to informed individuals and organizations, who will find it understandable once presented to them (McGaughey, 2002). However, not all component knowledge is equally easy to absorb, even for firms in similar situations, as it may run from the simple and explicit to the fairly complex and tacit. 
Architectural knowledge relates to an entire system of knowledge and the structures and routines for integrating its component knowledge into patterns for productive use and for developing new knowledge (Matusik \& Hill, 1998; McGaughey, 2002; Tallman et al., 2004). Not only is architectural knowledge typically complex and intangible, or tacit; it is also highly organization-specific and private due to its path-dependency, organizational embeddedness, and evolutionary nature, spillovers of firm-specific architectural knowledge are therefore not readily accessible by other firms (Matusik \& Hill, 1998). However, Tallman et al. (2004) propose that architectural knowledge develops also among the firms in a cluster, due to their close competitive, cooperative, and social interactions. They suggest that possessing such'quasi-private to cluster members' knowledge delineates membership of a cluster and supports commonality of local knowledge by improving the absorptive capacities of clustermember firms for each others' component knowledge.

Architectural knowledge may not be readily transferable, but this does not mean that it has no effect on the flow of knowledge. Similar architectural knowledge derived from similar conditions and activities improves the absorptive capacity of a firm for component knowledge developed in a similar firm (Tallman et al., 2004). In Saxenian's (1994) comparison of the Silicon Valley and Rte. 128 clusters in semiconductors, the architecture of the regional cultures was highly determinate of the ability of member firms to share technical knowhow. Henderson and Clark (1990) show that firms may be unable to grasp the competitive essence of new technical advances because of their own preconceptions about the architecture of the system, so movement of component knowledge between firms and clusters can also be limited by differences in architectural knowledge.

We propose that changes in knowledge stocks create new forms of knowledge and new resource configurations in both firms and clusters of firms. We specifically challenge the idea that architectural knowledge is immobile. Rather, firms can gain access to alternative 
architectures through foreign direct investment, either by locating in a cluster or by acquiring a unit that is engaged in a foreign cluster and 'bringing it home'. By doing so, multinational firms can significantly alter their own architectural understandings and access foreign component knowledge efficiently.

\section{The Initial Model and Key Propositions}

The concept of the cluster is based on the premise that firms which are located within a cluster have key similarities and are able to use these to achieve a greater level of competitive performance than those which are not (Porter, 1998). For instance, Saxenian's (1994) comparative study of the firms in Silicon Valley underlined how the fertile context of a restricted district (cluster) can provide competitive advantage, particularly in terms of the growth rates of the firms within one region as compared to another. These are underpinned by the notion that such clusters contain both passive and active collective efficiencies (Bell et al 2009). Passive efficiencies are those set out by Marshall (1920) and include aspects such as

reduced transportation and specialized labor pools. Active collective efficiencies are related to the availability of knowledge and other valuable intangible resources to which member firms actively seek access (Iammarino and McCann, 2006).

\section{P1: Firms within a cluster will outperform firms that are outside.}

However, the notion that knowledge and performance are solely and wholly bounded by geographic limits is clearly over-simplistic. Technology-focused clusters, or "new industrial districts" (Piore and Sabel, 1986), are not closed systems, but are dependent on external knowledge flows, often through the internal networks of multinational firms, to maintain and enhance their potency (Lawson, 1997). The literature of multinational investment suggests that multinational firms invest in clusters to access locally sticky knowledge (Mudambi, 2008). Networks of alliances have been shown to exist within clusters and to differentiate knowledge sharing activities (Markusen, 1999; Tallman and Jenkins, 2002), and 
geographically dispersed inter-firm networks are particularly influential in spreading knowledge and in explaining firm level performance (Mowery, Oxley and Silverman, 1996).

\section{P2: Knowledge-based clusters are characterized by strong intra-regional connections}

and also by connections to external, even international, knowledge sources and partners.

The economic geography literature tends to focus on the formation of clusters, which are seen as emergent and firms simply find themselves benefitting from such agglomerations without necessarily making deliberate attempts to exploit such potential (Piore and Sabel, 1986). Clusters in specific industries develop in specific locations based on historic factors and on the advantages of co-location for competitors in those industries (Zucker, Darby and Armstrong, 1998; Tallman and Phene, 2007). However, firms do not only develop within clusters, they also make strategic decisions to become participants. The international strategy literature has made much of the locational strategies of multinational firms and the implications of these choices for firm performance. Off-shore sourcing of both goods and knowledge development further emphasizes the importance of location-based comparative advantage, conceived in a narrow and precise manner, as the basis for competitive advantage among multinational firms (Mudambi, 2008; Doh, Buyaratavej and Hahn, 2008).

\section{P3: Multinational firms proactively implement strategies to take competitive advantage} of location-tied knowledge competencies in choosing to locate in specific clusters.

Studies in the area of alliances and knowledge suggest that knowledge flows more effectively within company structures and also between formal alliance partners, even within a cluster, as opposed to between informal partners or different organisations in the same industry with no formal linkages (Gomes-Casseres, Hagedoorn \& Jaffe, 2006; Almeida and Kogut, 1999). Studies of multinational firms provide considerable evidence that knowledge flows more easily within firm boundaries when moving across geographical distances or crossing national borders, as internalization by a firm reduces both fears of opportunistic 
behaviour in partners and improves joint understanding for more tacit knowledge (Gupta and Govindarajan, 2000). This contrasts with the rather more passive construct of spillovers of information within informal social networks that often characterizes work targeted at knowledge flows within geographically defined areas (Storper, 1995).

P4: Knowledge flows will be greater between formal partners and within multinational firm structures than through informal relationships.

Although the idea that firms within a cluster operate in a homogenous manner often is inferred from work on the cluster level of analysis, there is also a wide range of literature that suggests that firms position and configure themselves in different ways within clusters. Maskell (2001) distinguishes vertical (supplier-buyer) cluster relationships with a primary cooperative basis from horizontal cluster relationships that have a primary competitive basis. Markussen's (1999) idea of differing cluster structures underlines the potential variation in firm approaches, as does Tallman and Jenkins' (2002) description of multiple internal networks within a single regional cluster. Tallman et al. (2004) further establish that firms within a cluster retain private, firm-specific, architectural knowledge even as they participate in the cluster-specific architecture.

P5: Competing firms in the same industry, even the same cluster, will implement widely differing strategies to reconfigure core technologies in novel ways to build firm-specific advantage building on cluster-specific architectural knowledge.

To further understand the dynamics of capability-building at the level of geographical clusters we now look to the development and evolution of a particular form of motor sport Formula 1 - which is unusual in being able to allow us to consider both firm and regional levels of competitive performance, and which has featured geographical concentration in the construction of the racing automobiles as a characteristic of the industry from its birth. 


\section{Refining the Model: The Geography of Competition in Formula 1 (F1) from 1950 to 2008}

Formula 1 provides a unique opportunity to explore the performance of relatively complex, performance driven organizations that design, manufacture and race their own cars in an annual series of globally dispersed races. F1 provides a unique balance of technology, capital, and human resources with an unequivocal performance outcome - winning races - which makes it a particularly suitable sector for us to examine (Foxall and Johnston, 1991; Jenkins and Floyd, 2001; Jenkins, in press). First, we are able to examine relative firm performance in international competition over extended periods and thereby to identify firm level competitive advantage. Second, we are able to tie location of activities to these performance outcomes and thereby concern the potential for cluster type effects. Third, the evidence of a horizontal cluster of firms in the south of the UK is well documented and thereby provides at least one possible example of the potency and dynamics and clusters. Finally, the wealth of data, much of it focusing on the turbulent context of technological development and innovation (Wright, 2001) allows us to consider the role of knowledge flows in the process of achieving competitive performance.

\subsection{Research Method and Data}

This study draws on an extensive research database which has been built up over the last ten years. It was developed to focus on issues relating to competitive performance of individual teams, technological innovation and development and also the managerial and resourcing challenges of achieving and sustaining high performance. The database includes details of race performance from 1950 - 2008; inputs from several hundred specialist periodicals and other publications, books (including autobiographies of influential individuals) and over fifty interviews with key players in the industry conducted between 1999 and 2009, all of which have been recorded and transcribed. 
We describe our research approach as 'guided induction' as we use a series of a priori propositions to guide the way in which we have interrogated the database. This has involved breaking each proposition into a series of keywords and interrogating the database accordingly to identify relevant data sources that can be explored in more detail. In this particular study, we identified two in-depth interviews with individuals who were influential in different teams and different locations during this period. John Barnard was Technical Director of UK based McLaren (1981-1986) and Ferrari (1986-1990 \& 1992-1996), Ross Brawn was Technical Director of UK based Benetton (1991 - 1996) and Ferrari (1997 2006). Given their relevance to many of the questions we raise we have incorporated sections of these transcripts to illustrate the case study. This approach is an embedded case design (Scholz \& Tietje, 2002; Yin, 2003), as we select and explore embedded case units that reflect particular episodes in the history of F1 during the period in question.

The process we have adopted first maps out the shifts in performance at the firm and regional level between 1950 and 2008. This provides us with an overview of competitive performance during this time period. The data allow us to consider the issues related to the performance of firms and regions. In this case we have focused on race performance, this is the express objective of the F1 teams themselves and it also provides a close proxy to the economic success of individual firms, since financial rewards are derived directly from race performance. We use the concept of podium performance (the first, second and third cars to finish a race) as this is the most consistent way in which prize money has been allocated in the period 1950-2008 (Hotten, 1998).

Figures $1 \& 2$ provide an illustration of the location of F1 teams at two different points in time. Figure 1 illustrates the locations of the main Formula 1 teams at its beginning in 1950. These are identified as ERA based in Dunstable, UK; Talbot-Darracq based near Paris, France and Maserati, Ferrari and Alfa Romeo all clustered around Modena in northern Italy. 


\section{INSERT FIGURE 1 HERE}

Figure 2 shows the distribution of F1 teams in 2008. Here we see a stronger presence in the UK, particularly in the area to the north, west and south of London. The Italian grouping, although diminished, remains, as does the presence of activity in both Germany (BMW engines in Munich and Toyota car and engines in Cologne) and France (Renault engines at Viry-Châtillon).

\section{INSERT FIGURE 2 HERE}

\subsection{The Analysis}

In this section, we consider the five propositions developed in the literature discussion to provide a basis for reflecting on the technological development of F1 between 1950 and 2008 and to use the rich data from the case to explore these questions. The study is not deductive, in that these guiding questions have simply helped to bound our data gathering and analysis rather than result in a specific test of the propositions. The output should therefore be seen as exploratory and explanatory rather than conclusive and definitive. We use the case study to further refine, rather than accept or reject, the initial propositions. At the end of each section we offer a reconsidered statement of the proposition based on our assessment of the evidence from the case of Formula 1 racing.

\subsubsection{Proposition 1}

The first issue that we examine is the potential existence of clusters within this specialised industry context in the period 1950 - 2008. Much has been written about the existence and development of the UK's Motorsport Valley in terms of it being a particularly potent and influential cluster (Beck-Burridge \& Walton, 2000; Henry \& Pinch, 2002). We also consider the question as to whether or not clusters existed to the same extent in Italy, Germany and France. 


\section{INSERT FIGURE 3 ABOUT HERE}

The data presented in Figure 3 raises two initial questions. First, how many clusters are in evidence, and second, what is the relative performance of the firms within the clusters? Cooke (1999) links Marshall's concept of industrial districts to three elements: groupings of sub-contractors, readily available skilled labour and rapid formal and informal communication across firms and employees reflected by Marshall's notion of 'knowledge in the air'. We suggest that there in fact were two potential clusters in existence in the Formula 1 industry between 1950 and 2008. The first was an emerging Italian cluster which is evident between 1950 and 1957 and which built on the notion of the 'Land of Motors' between Modena and Bologna and which was comprised of motorsports operations, specialist sports cars and motorbikes. In his work on the region, Brusco (1986) notes how the performance of these small specialists is often not recognised in studies of regional economics as these tend to focus on higher overall levels of productivity and output.

There is evidence of both vertical and horizontal cluster-like activity relating to the motorsports activity in this region during this period - in particular related to the racing car design expertise which developed in Alfa Romeo and was then exploited by Ferrari and Lancia (Yates, 1991).

Many of the engineers that became famous in the region provided expertise that was utilised by many different companies. For example, Gian Paolo Dallara started his motorsport career at Maserati with Ramirez and then established the Lamborghini sports car operation before founding his own company, Dallara, which went on to become a successful single seat race car manufacturer (Henry et al, 2007). Further evidence of the 'untraded interdependencies' of this region of Northern Italy is provided by the technology which moved between Lancia and Ferrari, when Lancia decided to withdraw from F1 at the end of 
1955, in an arrangement brokered by Fiat they allowed Ferrari to use the designs of their D50 car in order to create the Ferrari D50 of 1956 (Yates, 1991).

If the nascent Italian motorsports cluster dominated F1 in the early 1950s, it soon evolved into a vertical cluster consisting of a supply network tied to a single team - Ferrari. In contrast, the second cluster emerged in the UK around the dominant Cooper team in the late 1950s, and was taken forward by Lotus and others in the mid sixties, this grouping, known as Motorsport Valley (MSV), became characteristic of the archetypal horizontal cluster with differing firms coming to the fore in different periods. In particular Lotus dominated much of the 1960s and 1970s (Crombac, 1986); McLaren the 1980s (Henry, 1999) and Williams the 1990s (Hamilton, 2009).

The statement in P1 is supported by much of the activity during the period when the clustered firms from the UK dominated the F1 races. However, we can observe particular periods when individual firms broke through and dominated the cluster firms. One of these is during the mid-1970s and the other in the period between 1999 and 2008. In this case we suggest the following phenomena occurred: 1) The Italian motorsport cluster began to develop in the early 1950s, but due to various environmental shifts failed to become truly dominant in a sustained way. The Italian motorsport cluster effectively transformed from a nascent multi-firm cluster into a single-firm centric vertical cluster (Markusen, 1999; Maskell, 2001) based around Ferrari, but with a number of other F1 operations developing in the region such as Dallara, Minardi and Alfa Romeo. 2) The English cluster displayed the characteristics of a horizontal, or competitive, cluster and also demonstrated temporary phases of firm level success, but with consistent cluster domination from the period 1958 through 1973 and from 1980 through to 1999. 3) The domination of Ferrari in particular periods suggests that at times the dominant-firm vertical network outperformed the broader horizontal cluster due to 
asymmetries in knowledge firms between these regions. Knowledge flows from the UK to Ferrari, through both targeted hires and direct investment by Ferrari in the UK, allowed it to build up architectural knowledge in key technologies, but there is little evidence of reciprocal flows back to the UK cluster, supporting any competitive advantage Ferrari was able to develop during this period.

F1 shows that while as a group the competing firms located within a horizontal cluster dominated the industry, they were susceptible to competition from a vertical, or dominantfirm, cluster in which one central firm was supported by a network of supplier firms and other organizational relationships (Maskell, 2001; Zucker et al., 1998). For multinational firms considering locations in which to seek knowledge, this presents both insight and warning short term success may not represent long term competitive advantage nor long term superior knowledge production.

\section{Revised P1: The set of firms within a horizontal cluster generally will outperform} external firms. However, when performance is considered at the firm level, 1) varying firms within a cluster will demonstrate competitive advantage at different times, and 2) external competing firms can gain advantage and out-perform firms located within a cluster for a period.

Thus, we find that firms appear to retain an important degree of distinctiveness within clusters, with the result that circulating component knowledge of technological innovations does not benefit all member firms equally. However, the rapid spillover of such innovation suggests that competitive advantage resides with more deeply embedded capabilities, perhaps what Tallman et al. (2004) define as "firm specific architectural knowledge", and describe as being unavailable to other cluster members. They propose a similar limitation on the movement of knowledge across cluster boundaries. However, from our evidence it does appear that externally located firms can tap the component knowledge of distant clusters, as 
Ferrari did by using UK-based subcontractors, and combine such knowledge with their own distinctive competences to achieve superior performance. The lack of co-located competitors then permits these firms to sustain advantage longer than is typically the case for clusterembedded firms (Maskell, 2001). This suggests that multinational firms can indeed expect to benefit competitively from sourcing cluster-tied knowledge and combining it with other knowledge in remote locations, as proposed by Kogut and Zander (1992).

\subsubsection{Proposition 2}

We consider the performance results described above to be the consequence of knowledge flows both within and between clusters and external competitors. To demonstrate this, we first consider the nascent Italian cluster in the period 1950-1957. Here there is very little evidence of any international knowledge sources or partnerships beyond the cluster. It may be that such external linkages are likely to develop later in the evolution of a cluster rather than in the early stages. And indeed, we note later evidence of Ferrari accessing knowledge from Motorsport Valley in the UK through direct investment in a research facility. One of the first indications of this was that the first monocoque chassis that Ferrari used in 1972 actually was made for them by an English sub-contractor for the 312B3 (Yates, 1991). This was followed up later, when in 1986 Ferrari recruited Technical Director John Barnard to the team:

"Ferrari was one of those teams that was fundamentally an engine company and the chassis was always second place and he [Enzo Ferrari] saw what was going on in the British side of Formula 1 with the introduction of composites and so on, so he wanted to lift the chassis side really. He, through intermediaries, contacted me and the outcome was that I didn't want to go to Italy but he wanted me so he said "Okay, do you want to set something up in England?" and given that opportunity I said "Yes”. (John Barnard, Interview).

Ferrari were accessing very specific technologies (chassis design with the 312B3) and knowledge from Barnard and his team of composite materials and aerodynamics with the 
GTO operation. However these were temporary phenomena, and once this knowledge had been absorbed, the operations were moved back to Italy:

“Montezemolo [President of Ferrari] had decided that Ferrari wasn't being pulled together from both sides, the English end and the Italian end weren't being pulled together so they got John Todt [New General Manager of the F1 operation] along and right from when he came in initially Todt basically said to me "Look I want it all back in Italy" (John Barnard, Interview)

In the evolution of the UK cluster, a different pattern of international linkages and knowledge flows is evident. First, many of the technologies used in the early Cooper cars of the 1950s came from outside the UK, such as the Fiat Topolino suspension components or the JAP motorcycle drive chain (Lawrence, 1998). However, once this technology was assimilated into the cars, there is no evidence of any further direct international knowledge inflows.

In the late 1970s, both Lotus and McLaren were exploring the use of carbon composite material to create an F1 chassis. Lotus had determined to use a 'hand laid' solution where the composite was laid by hand. McLaren's John Barnard felt that a strong and lighter structure would be created by moulding rather than hand laying the carbon. He had tried to locate expertise in composites in the UK, but had been unsuccessful:

"I started thinking about this carbon thing and went to have a look round at British Aerospace in Weybridge and see what they were doing, (John Barnard, Interview)

Barnard had worked for a number of years in the US for the Chaparral racing team and utilized this network to locate an organization in the USA who would be able to help with the molding process: 
"the next day we got on a plane with the model under our arm, put the model in the overhead rack, got on the plane with the drawings and we were both off to Salt Lake City and that was it, (John Barnard, Interview)

In this case we can detect international knowledge sourcing processes both of firms within a cluster looking outside (McLaren using the composite expertise in the US), and of isolated firms looking inside the cluster to access particular knowledge (Ferrari establishing a design operation in the UK). This suggests the following amended Proposition 2:

\section{Revised P2: Linkages within a cluster allow member firms to access knowledge and} capabilities within the cluster. However, external competitors seek specific technologies from clusters and cluster member firms and use international, networks to create at least temporary firm-specific competitive advantage.

One way in which clustered firms seem to distinguish themselves from co-located competitors in a horizontal cluster is by firm-specific external linkages (see also Tallman and Jenkins, 2002), often to multinational firms. Such linkages develop firm-level architectural knowledge, and thereby provide technical component knowledge that may be less accessible to other cluster members than locally-developed technology. The main focus of clusteroriented studies of knowledge (Pinch et al., 2003) is on the isolating effect of differential architectural knowledge. However, it appears that external firms can access component knowledge held in clusters through mechanisms such as alliances or contracts with cluster members that can circumvent ignorance of local architectural knowledge. The evidence suggests that Ferrari typically resisted such MSV-sourced knowledge until its benefits in racing became obvious, but would then engage key owners of the knowledge rather than trying to develop something similar on their own. This insight suggests that multinational firms can indeed access even highly tacit knowledge through location in a geographical cluster if they are willing to engage closely with local suppliers and competitors. 


\subsubsection{Proposition 3}

When Honda, the Japanese multinational automobile firm, considered entering F1 in the early 1960s, they went to Brabham, to Cooper and to Lotus to see if these British teams could build a chassis to take a new engine they had just completed. Their original plan was to provide an engine for a British constructor to use, ultimately the plan didn't work due to politics between the British Constructors and their engine suppliers, but Honda had a clear objective to utilise the expertise within this region: "Honda had begun thoroughly, sensibly and discreetly by asking advice from people who knew... Nakamura [Chief Engineer at Honda] and Crombac [French Journalist who had helped organise the Japanese Grand Prix in 1963] did not only visit Brabham. They went on to Cooper, then Lotus.” (Hilton, 1989: 15).

Ilmor was founded in January 1984 with the objective to build an engine for the North American Indy car series. They were able to secure backing from Roger Penske, a US racing team owner who the owners met while they were working for Cosworth. Penske's Indy racing headquarters was based in Reading, Philadelphia, USA but they also had a chassis building operation based in Poole, Dorset, UK. Penske put up the initial capital for the project and in return received half of the shares in the business, he was then able to secure further funding from General Motors to badge the engine as a Chevrolet (Beck-Burridge \& Walton, 2000; Couldwell, 2003).

In 1998 Mercedes badged Ilmor engines won the F1 constructors world championship with McLaren and the drivers' championship for Mika Hakkinen. The reason why Mercedes Benz used Ilmor was summarized by Board member Jürgen Hubbert in 1996: "We could build an engine that would be powerful and strong. But the trouble would come when it took three hours to change the engine in the car! It's not just about power. It's how to build the engine, the dimensions, the weight, having the centre of gravity in the right place, and making it so an engine can be changed in forty-five minutes. Ilmor had the knowledge to bring these 
things together and we had no doubt that this was the way forward for us.". (Spreckley, 1999: 146)

Towards the end of the 1990s, major shifts in ownership began to take place with car manufacturers taking major stakes in the MSV teams. Renault acquired the Benetton team in 2001. DaimlerChrysler (Mercedes) had bought $40 \%$ of McLaren's holding company and also a similar portion of their specialist engine supplier, Ilmor. Toyota made the decision to enter F1 from scratch from their motorsport base in Cologne, after spending a year developing their prototype car at the F1 circuits during 2001 and Honda entered in 2005 through the acquisition of the British American Racing (BAR) Team based at Brackley in the UK. All of these activities point towards an endorsement of Proposition 3 that firms, and particularly multinational firms, will choose to locate in clusters to access specific knowledge. There are of course exceptions to this. Toyota chose to deliberately locate outside the cluster in order to make use of their specialist motorsport facility located in Cologne - Team Toyota Europe or TTE. For many commentators this decision explained why their F1 activity had been relatively unsuccessful despite significant levels of investment (Jenkins et al 2009). BMW also followed a similar route when they prematurely ended a relationship to supply the Williams team with engines to make an acquisition of the Sauber team based in Hinwil, Switzerland as they regarded the potential for a closer cultural and geographic fit between BMW and Sauber than with Williams.

\section{Revised P3: Multinational firms proactively implement strategies to access}

\section{location-tied knowledge competencies by choosing to locate operations in specific} clusters or alternatively by creating networks outside their home clusters.

F1 has offered situations where members of the horizontal MSV cluster reach out to suppliers from worldwide locations, and where companies from around the world reach into MSV for particular skills in building engines and chassis, an expertise in race car design that 
is the basis for the existence of MSV. Ferrari was able to overcome its architectural inclination to ignore British technological advances in the face of persistent losses, but further evidence suggests that the benefits of cluster-based competences in F1 were widely recognized, and also that external partners recognized the differential skills of internal companies, distinguishing between, for instance, Jordan (a secondary competitor) and McLaren (a significant innovator) within the MSV cluster. The importance to multinational firms of location for access to novel firm-specific skills is supported, but our evidence suggests that multinational firms must understand the differences among members of a location-tied cluster if they are to benefit from cluster access.

\subsubsection{Proposition 4}

As many of the F1 Teams are satellite operations of the multinational automotive manufacturers we are able to explore the concept of 'within company structures' and the potential they may offer. Ross Brawn, has been technical director for several F1 teams, including Ferrari, and in 2009 owner of his own F1 team, Brawn GP. In 1997 Brawn moved from the Benetton F1 team, an independent operation located within MSV to Ferrari, owned by the Fiat Group and whose operation in Maranello also included a separate organisation to design and manufacture road going Ferrari cars:

Quality control in motor racing is not as good as I experienced when I came here because the quality control was necessary for a road car group, things like quality control at your suppliers was new to me. I knew it existed but we have quality control engineers and, I'm not sure what they're called, but we have people who are working with our suppliers to ensure quality all the way through the line(Ross Brawn: Interview)

Brawn also elaborated on how he had managed to unlock some of the potential of the Fiat Group that prior to his arrival had been underutilised: 
One of the benefits we've got from Fiat is a Research Group and Centre Research Fiat $(C R F)$ which is an independent part of the organisation. It's been a huge asset to us and it really wasn't being used when I came here and we were lucky that [another member of the team] had come from there and kept telling me what a wonderful place it was and how we should use it and he knew the right buttons to press and the right people to talk to and they'd had a little bit of a difficult relationship in the past with CRF but we managed to build it up and now it's a key part of our organisation.

Brawn also hinted at some of the potential reasons why these opportunities had not be realised in the past:

We have a little bit of bureaucracy that comes from being part of a large group and that's frustrating sometimes but you have to accept that as part of the necessity of being part of a large group. (Ross Brawn, Interview)

\section{Revised P4: Knowledge flows will be greater between formal partners and within} company structures than through informal relationships, but such formal flows can be facilitated or inhibited by informal relationships.

While most of the discussion of knowledge flows in clusters emphasizes informal relationships, uncompensated spillovers, or untraded interdependencies (Zucker et al., 1998; Storper, 1995), the experiences of firms and individuals in F1 demonstrate the importance of formal relationships, whether alliances, subcontracting, or technology supply contracts. For one thing, formal relationships ensure that accurate and complete component knowledge is shared - a concern in the case of informal ties, where rumor and partial revelation are more likely. In cases such as Ferrari deciding to commit to aerodynamics or other system-level architectural redefinitions, access to full and complete knowledge seems particularly important. However, it is suggested that the above is moderated by the informal relationships that exist around the formal knowledge flow. The benefits to external firms of informal ties to 
members of clusters seem undeniable, but more in support of formal ties that provide fully compensated access to complete bodies of knowledge than as substitutes for contractual ties.

\subsubsection{Proposition 5}

In the Formula 1 case we can discern two quite distinctive sets of architectural knowledge which give emphasis to different areas of component knowledge. In the nascent Italian cluster, we can see a clear focus on engine design as the central element of racing car design, an architecture which endures in the history of Ferrari in its vertical cluster. In the British cluster, we see first an emphasis on chassis design and weight distribution (to improve the handling of the car) which is followed by aerodynamics and the use of composites on the part of all competitors. In the later part of the period, we suggest a significant shift in the architectural knowledge of Ferrari to provide a more balanced understanding of the areas of engine, chassis and aerodynamics.

Founder and CEO of Lotus, Colin Chapman's philosophy of starting the design process with the chassis put him in direct contradiction with the Italian F1 teams such as Ferrari, as driver Nigel Mansell, who had worked for both observed: "Enzo Ferrari believed that the engine was the most important part of the racing car; Colin [Chapman] believed it was the chassis." (Mansell, 1996: 126).

By 1960, the dominance of the British mid-engine concept was clear. Up to this point, Enzo Ferrari had resisted this innovation, maintaining that the engine should always be in front of the driver, supporting his position with the often repeated the expression that the ' $o x$ pulls the cart' (Yates, 1991: 282). However, the evidence from race results was undeniable, and Ferrari had to build a lighter mid-engine car, which they did with the Tipo 156 'sharknose'to win a further world title in 1961. However Chapman was to take his ideas on chassis development a stage further in 1962 with the development of the Lotus 25 monocoque chassis, using a fabricated structure rather than a tubular frame to form the chassis - a concept 
that was quickly adopted by the other teams based in MSV (Lawrence, 1998). The advances made in chassis construction by the MSV teams created problems for Ferrari (Nye, 1977), so that not until 1964 was the Ferrari 158 was launched with a monocoque type chassis similar to the Lotus 25 of 1962, suggesting that Ferrari were two years behind MSV technology.

However, the most significant blow to Italian performance was to come with the Ford DFV engine. This was first used competitively in a Lotus 49 at the Dutch Grand Prix in 1967 and caused a sensation by winning its first race (Robson, 1999). The Ford DFV was created by a joint venture between the Ford Motor Company, who funded the project, Cosworth Engineering, based in Northampton, UK, who designed and built the engine, and Lotus, based in Norfolk, who developed the Lotus 49 using an innovative 'semi-monocoque' design where the monocoque finished just behind the driver allowing the engine to form a structural part of the car thereby reducing weight and maximizing rigidity (Robson, 1999).

Although the original intention was for the Ford DFV to be supplied exclusively to Lotus, Ford made the decision to make it available to other F1 teams in 1968 (Crombac, 1986). It dominated F1 through the early seventies and created a significant growth in the number of F1 constructors based in MSV. In 1969 and 1973, a car with a Ford DFV engine won every Grand Prix, the only occasions in the history of F1 that a single engine totally dominated a season. Effectively, the DFV meant that the MSV teams could focus on chassis performance and then acquire a highly competitive engine at relatively low cost (Jenkins et al, 2009).

The late 1970s and early 80s were dominated by a radical shift in F1 car design ground-effect aerodynamics. Aerodynamics had been developed by the MSV teams in an effort to increase grip, using aerodynamic devices known as 'wings' to increase downforce as velocity increased - the opposite to lift created by the wing of an aircraft. Ground-effect took things a stage further by using the air flowing under the car to create a low pressure area 
which effectively sucked the car onto the track. This innovation was led once again by Lotus (Crombac, 1986; Wright 2001).

The Lotus 79 won the 1978 world championship, establishing ground-effect technology as a dominant concept in F1 - driver Mario Andretti described the car as being 'painted on the road' (Crombac, 1986: 284). Many constructors subsequently attempted to imitate the design. Quick imitation was practical for many teams, as the majority was using the same engine configuration as Lotus [Ford DFV] and therefore had only to concentrate on re-design of the chassis. The narrow profile Ford V-8 was ideal for this application. Ferrari's commitment to the Flat-12 engine meant that they were unable to create the narrow chassis profile needed to locate the ground-effect venturi passage on either side of the engine, and as a result Ferrari became uncompetitive during 1977 and 1978. However Lotus themselves found that their competitors within MSV, in particular Williams, had developed a more effective version of the design, as summarized by former Lotus Technical Director Martin Ogilvie:

... and then of course Williams went and thought about it and then came up with a much better car mainly because they realized the importance of the chassis structure in creating downforce. (Martin Ogilvie: Interview)

The above charts the shift in the architectural knowledge of the UK cluster between a focus on chassis to develop to one which integrated both chassis development and aerodynamics. During this period (1980s and early 1990s) Ferrari were uncompetitive and so embarked on a program of radical change which involved bringing in new leadership and also locating the design operation back in Maranello. Ross Brawn, Technical Director of Ferrari, summarizes some of the key reasons for Ferrari' return to success in the early 2000s as:

If we had an innovation here it's the fact that we combine the engine and the chassis together as one whole but we apply that principle to all areas of the car with the electronics, the engine, the chassis, the aerodynamics, the structure, it all had to be a whole there was no 
point in having one area very strong and the other area weakA Ferrari is a Ferrari, it's not an engine, it's not a chassis, it's not an aero package, it's a Ferrari. (Ross Brawn: Interview).

This integrated approach to car design allowed Ferrari to dominate F1 up until 2004, at which point two MSV based teams, Renault and McLaren, were starting to make inroads by following the Ferrari approach of integrating engine, chassis and aerodynamics development. Both of these teams had their own dedicated engine operations. McLaren used the Ilmor operation which subsequently became wholly owned by Mercedes Benz and renamed Mercedes Benz High Performance Engines. Renault F1 engines were designed and manufactured at Viry-Châtillon near Paris, however a small engine design team were also colocated at their main F1 design and assembly operation at Enstone in Oxfordshire in order to ensure that the design process was as integrated as possible. The competition among these three teams continued to the end of the period, with Ferrari securing the constructors championship in both 2007 and 2008.

\section{Revised P5: Competing firms in the same cluster can use unique firm-specific architectural knowledge to build competitive advantage while applying cluster-specific knowledge. External or multinational firms with very different architectural knowledge are slower to integrate knowledge developed in clusters.}

In the case of Formula 1, we see this phenomenon in several situations. In particular, Lotus was the source of the innovations such as semi-monocoque construction, ground-effect aerodynamics and the use of composite materials. However, Lotus found only limited competitive success from these innovations as other MSV firms quickly understood and incorporated them into their own repertoires of capabilities. Ferrari, the sole surviving Italian firm after 1957, was slow to recognize the potential value of each of these innovations, largely because its engine-focused architectural understanding of racing success simply failed to comprehend the potential value of chassis and body-related innovations. We might also 
consider that the loss of its regional competitors had reduced the direct pressure on Ferrari to innovate during this period, limiting its immediate incentive for disruptive architectural change (Maskell, 2001). For multinational firms seeking cluster-based knowledge, this insight suggests a patient approach to strategic re-combinations of knowledge (Kogut and Zander, 1992), as full understanding of captured knowledge is an involved and difficult process.

\section{Conclusions}

Our examination of the evolutionary patterns in the performance of clusters, networks and firms has provided a further refinement of some of the potential relationships that both support and change the nature of clusters and the opportunities available for multinational firms when choosing the location of new operations. The revisions to our initial propositions suggest that there is a symbiotic relationship between clusters and firms' external networks. These relationships allow the development of new knowledge and capabilities within clusters, but also allow external or multinational firms to access such capabilities and to develop their own distinctive resource combinations that may allow them to outperform the cluster-based firms.

Multinational firms, therefore, should consider current knowledge stocks to establish whether location within a cluster will bring greater benefit due to knowledge inflows than the outflows which could shorten the potential time period of a competitive advantage.

However, linkages between cluster based and external firms are an inherent part of the dynamics of the. Multinational entrants to clusters benefit the clusters as well as themselves.There may be strong reasons which relate to protecting proprietary knowledge or to ensuring cultural fit (as was the case with BMW and Sauber) which means MNEs choose not to locate within a cluster. Also, when establishing ties to cluster members, multinational firms must recognize that these are not homogenous - only a few of the cluster members are 
likely to be the real innovators.Although at a macro level the importance of formal structures to enhance knowledge flow may be regarded as self-evident, the Ferrari experience suggests that formal relationships may only become powerful sources of knowledge if the appropriate informal structures and relationships are in place. This suggests that competitive advantage at the MNE level may be dependent on the ability to support formal structures with informal mechanisms and relationships to enhance such processes.

Finally, we suggest that a key part of the challenge for MNEs in managing knowledge flows within clusters is ensuring that their architectural knowledge is sufficiently able to connect with cluster level knowledge and thereby benefit from the inflows from spillovers, but also sufficiently distinctive and private to ensure that some level of competitive advantage can be achieved. This is an important and subtle distinction and one which warrants further exploration in other technological sectors to define how such a balance can be achieved and maintained.

Our study has distinct limitations. It addresses a single industry, one that is in many ways unique, and our propositions need to be applied in other contexts. It is based on combining varying types of data in the case analysis, with the focus on developing theoretical frameworks rather than testing them. Cross-industry quantitative empirical studies of international samples of clusters, firms and networks are needed to confirm or deny fully our propositions. However, this unique context does allow us to consider a wide range of data and phenomena at both the cluster and firm level of analysis, such a rich description of a particular situation being particularly valuable for theory development.

Our study suggests that multinational firms can realistically hope to benefit from uprooting, transporting, and recombining even architectural knowledge from within clusters but only with difficulty and awareness of the pitfalls and the prospects. The value to a firm based in one location of incorporating ideas and innovations from another location, 
particularly a location that provides the shared, integrated knowledge of a cluster, can be very high, especially when the core architectural knowledge being imported is more distinctive. However, in F1, as in other cases, it seems that the greater the potential value, the greater the difficulty of transmitting knowledge from a firm or cluster in one place to a firm or cluster in another place. Seeking advantage by seeking exotic knowledge in far-flung locations is a strategy that is being proposed more often for multinational, but should be subject to careful scrutiny before being implemented - its costs are high and its benefits seem uncertain from what we observe in the world of Formula 1 racing. 


\section{References}

Almeida P. and Kogut, B. (1999). 'Localization of knowledge and the mobility of engineers in regional networks'. Management Science 45, 905-917.

Bell, S.J., Tracey, P. and Heide, J.B. (2009). 'The organization of regional clusters'. Academy of Management Review, 34, 4, 623-642.

Beck-Burridge, M., Walton, J. (2000). Britain's Winning Formula: Achieving World Leadership in Motorsports. London: Macmillan Press Ltd.

Brusco S. (1986). Small firms and industrial districts: The experience of Italy. In: Keeble D. and Wever E. (eds) New Firms and Regional Development in Europe. London: Croom Helm. Bradbury.

Cohen, W.M., Levinthal, D.A. (1990). 'Absorptive capacity: a new perspective on learning and innovation'. Administrative Science Quarterly, 35, 128-152.

Cooke, P. (1999). The co-operative advantage of regions. In Barnes, T.J. and Gertler, M.S. (eds). The New Industrial Geography: Regions, Regulation and Institutions. London: Routledge. 54-73.

Crombac, G. (1986). Colin Chapman: The Man and his Cars. Wellingborough, UK: Patrick Stephens.

Damanpour, F. (1991). 'Organizational innovation: A meta-analysis of effects of determinants and moderators'. Academy of Management Journal. 34, 555-590.

Doh, J.P., K. Bunyaratavej, and Hahn, E.D. (2008). 'Separable but not equal: The location determinants of discrete offshoring activities', Journal of International Business Studies, forthcoming.

Foxall, G.R. and Johnston, B.R. (1991). 'Innovation in grand prix motor racing: the evolution of technology, organization and strategy'. Technovation 11, 387-402.

Gomes-Casseres B, Hagedoorn J, Jaffe A. (2006). 'Do alliances promote knowledge flows?' Journal of Financial Economics, 80, 5-33.

Gupta, A.K. and Govindarajan, V. (2000). 'Knowledge flows within multinational corporations'. Strategic Management Journal, 21, 473-96.

Hamilton, M. (2009). Williams: The legendary story of Frank Williams and his F1 team in their own words. London: Ebury Press.

Henderson, R. M. and Clark, K. B. (1990). 'Architectural innovation: The reconfiguration of existing product technologies and the failure of established firms'. Administrative Science Quarterly, 35, 9-30.

Henry, A. (1999). McLaren: Formula 1 Racing Team. Yeovil: Haynes. 
Henry, N. and Pinch, S. (2002). 'Spatializing knowledge: Placing the knowledge community of Motor Sport Valley’. In: Huff, A.S. and Jenkins, M., (Eds.) Mapping Strategic Knowledge, 137-169. London: Sage.

Henry, N., Angus, T., Jenkins, M. \& Aylett, C. (2007) Motorsport Going Global: The Challenges Facing the World's Motorsport Industry. Basingstoke, Palgrave Macmillan.

Hilton, C. (1989). Conquest of Formula 1: The Inside Story of the Men who took Honda to Victory. Wellingborough: Patrick Stephens Limited.

Hotten, R. (1998). Formula 1: The Business of Winning. London: Orion Business.

Iammarino, S. and McCann, P. (2006). 'The structure and evolution of industrial clusters: Transactions, technology and knowledge spillovers'. Research Policy, 35, 1018-1036.

Jenkins, M. (In Press). 'Technological discontinuities and competitive advantage: A historical perspective on Formula One motor racing'. Journal of Management Studies, forthcoming.

Jenkins, M. and Floyd, S.W. (2001). 'Trajectories in the evolution of technology: A multilevel study of competition in Formula One racing'. Organization Studies, 22, 945-969.

Jenkins, M., Pasternak, K. and West, R. (2009). Performance at the Limit: Business Lessons from Formula 1 Motor Racing. $2^{\text {nd }}$ Edition. Cambridge: Cambridge University Press.

Kogut, B. and Zander, U. (1992). 'Knowledge of the firm, combinative capabilities, and the replication of technology'. Organization Science, 3, 383-97.

Lawrence, M. (1998). Grand Prix Cars 1945-1965. Croydon: Motor Racing Publications.

Lawson, C. (1997). 'Towards a competence theory of the region'. Cambridge, UK. ESRC Centre for Business Research Working Paper No. 81.

Mansell, N. (1996). Nigel Mansell: My Autobiography. London: Collins Willow.

Markusen, A. (1999). 'Sticky places in slippery space'. In The new industrial geography, Barnes TJ, Gertler MS (eds). Routledge: London, 98-126.

Marshall, A. (1920). Principles of economics, $8^{\text {th }}$ ed. London: MacMillan.

Matusik, S. and Hill, C.W.L. (1998). 'The utilization of contingent work, knowledge creation and competitive advantage'. Academy of Management Review, 23, 680-697.

Maskell, P. (2001). 'Towards a knowledge-based theory of the geographical cluster'. Industrial and Corporate Change, 10, 921-943.

McGaughey, S.L. (2002). 'Strategic interventions in intellectual asset flows'. Academy of Management Review, 27, 248-274.

Mowery D, Oxley J, Silverman B. (1996). 'Strategic alliances and interfirm knowledge transfer'. Strategic Management Journal, 17, 77-91. 
Mudambi, R. (2008). 'Location, control and innobation in knowledge-intensive industries'. Journal of Economic Geography, 8, 699-725.

Mudambi, R. and Navarra, P. (2004). 'Is knowledge power? Knowledge flows, subsidiary power and rent seeking within MNCs'. Journal of International Business Studies, 35, 385406.

Nye, D. (1977). 'Forza Ferrari'. Autosport (March 17), 26-28.

Pinch, S., Henry, N., Jenkins, M. and Tallman, S. (2003). 'From 'industrial districts' to 'knowledge clusters': a model of knowledge dissemination and competitive advantage in industrial agglomerations'. Journal of Economic Geography, 3, 373-388.

Piore, M. \& Sabel, C. 1984. The Second Industrial Divide. New York: Basic Books.

Porter, M.E. (1998). 'Clusters and the new economics of competition'. Harvard Business Review, 77-90.

Pouder, R. and St John, C.H. (1996). 'Hot spots and blind spots: Geographical clusters of firms and innovation'. Academy of Management Review, 21, 1192-1225.

Robson, G. (1999). Cosworth: The Search for Power. Yeovil, Somerset: Haynes Publishing.

Saxenian, A. (1994). Regional Advantage: Culture and Competition in Silicon Valley and Route 128. Cambridge, MA: Harvard University Press.

Scholz, R. and Tietje, O. (2002). Embedded Case Study Methods: Integrating Quantitative and Qualitative Knowledge. London: Sage Publications Inc.

Spreckley, N. (1999). Ilmor Racing Engines. Northampton, UK: Ilmor Engineering Ltd.

Storper M. (1995). 'The resurgence of regional economies, ten years later: the region as a nexus of untraded interdependencies'. Journal of European Urban and Regional Studies, 2, 191-221.

Tallman, S. and Fladmoe-Lindquist, K. (2002). 'Internationalization, globalization, and capability-based strategy'. California Management Review, 45, 116-35.

Tallman, S. and Jenkins, M. (2002). 'Alliances, knowledge flows, and performance in regional clusters'. In F. Contractor, P. Lorange (Eds.), Cooperative Strategies and Alliances. Oxford : Elsevier Science, 163-188.

Tallman, S., Jenkins, M., Henry, N. and Pinch, S. (2004). 'Knowledge, clusters and competitive advantage'. Academy of Management Review, 29, 258-271.

Tallman S, Phene A. (2007). 'Leveraging knowledge across geographic boundaries'. Organization Science, 18, 252-260.

Wright, P. (2001). Formula 1 Technology. Warrendale, PA: Society of Automotive Engineers. 
Yates, B. (1991). Enzo Ferrari: The Man and the Machine. London: Doubleday.

Yin, R.K. (2003). Case Study Research, Design and Methods. 3rd ed. Beverly Hills, CA:

Sage Publications.

Zucker L, Darby M, Armstrong J. (1998). 'Geographically localized knowledge: Spillovers or markets? Economic Inquiry 36, 65-86. 
Figure 1: Location of main Formula One Entrants, 1950

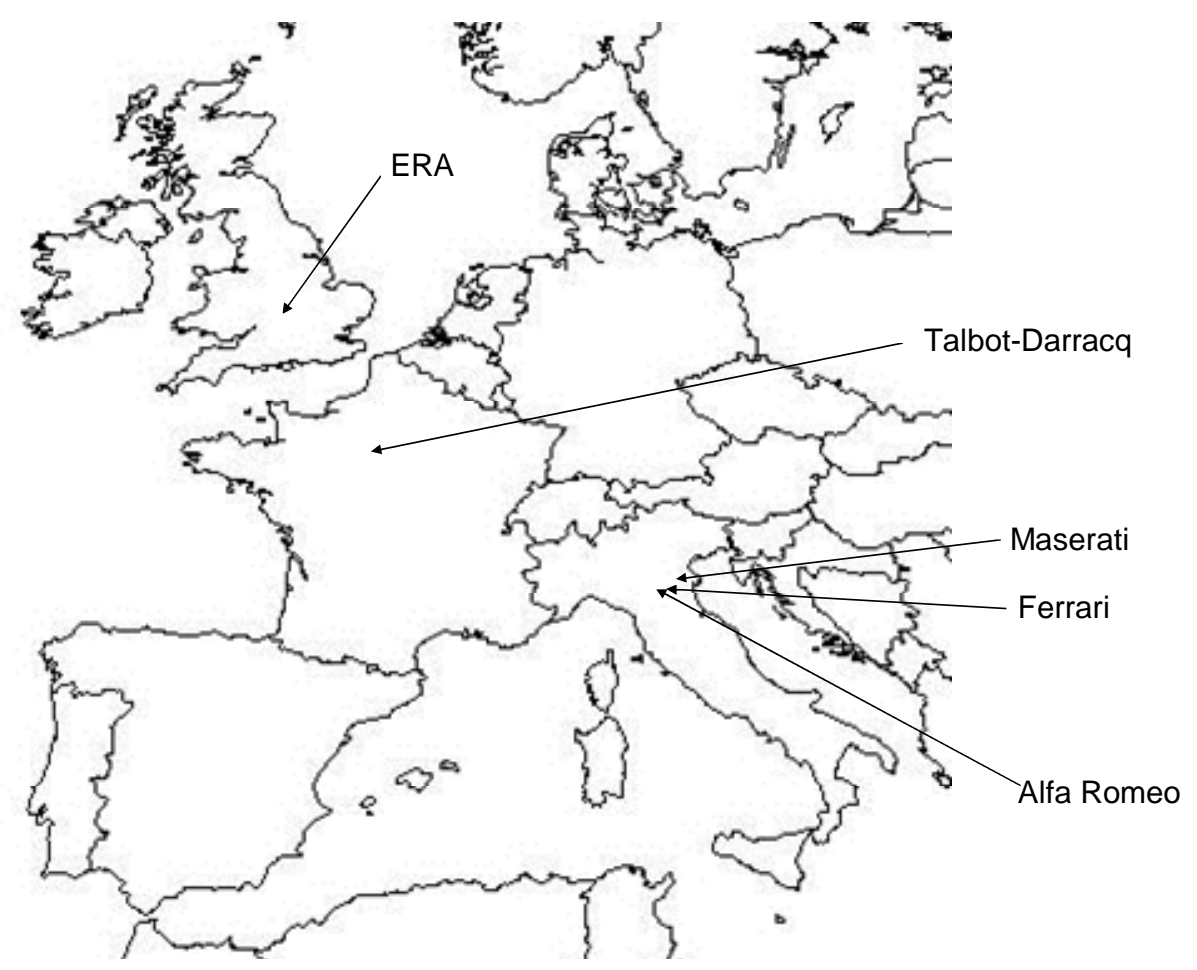


Figure 2: Location of Formula One Entrants, 2008

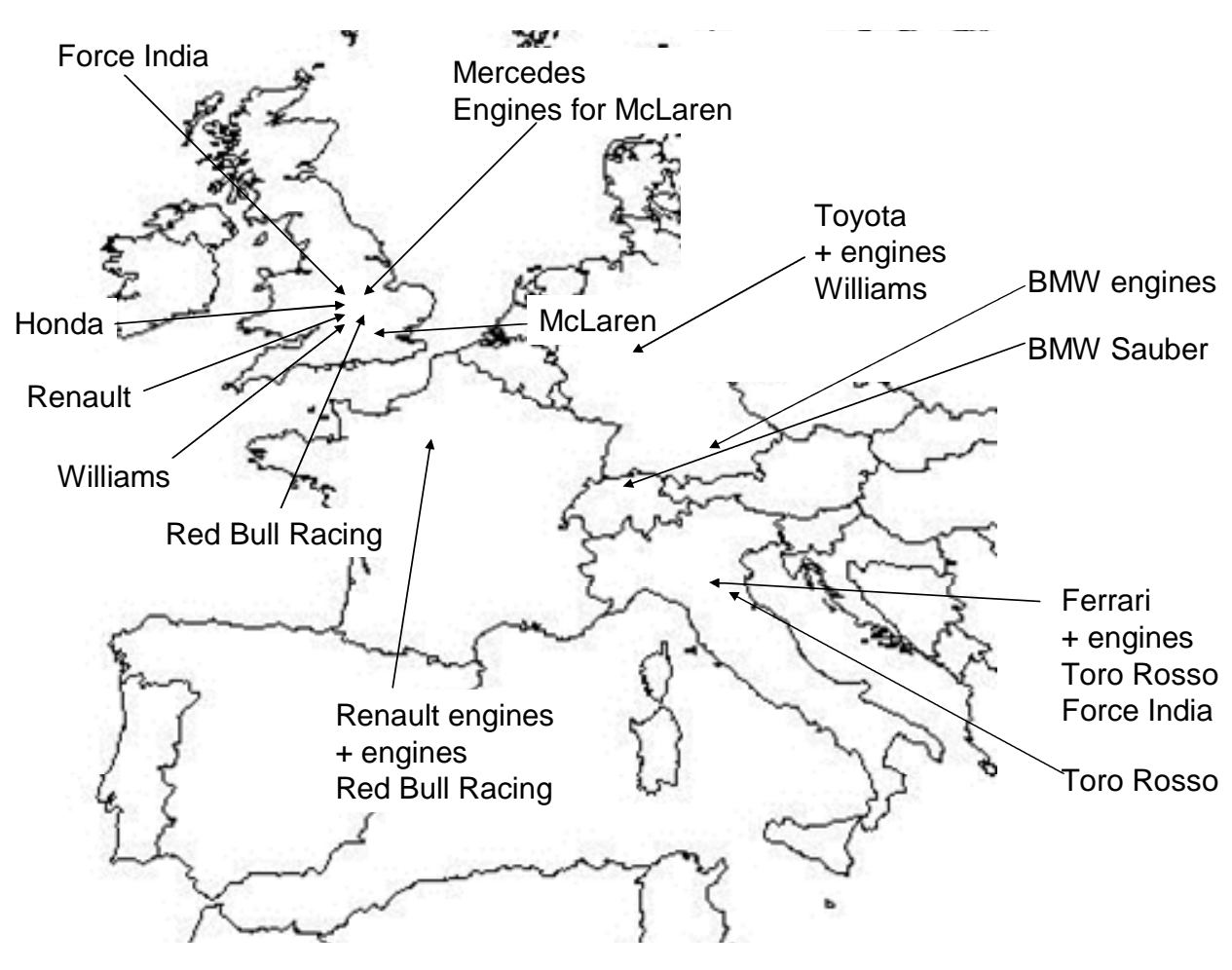


Figure 3:

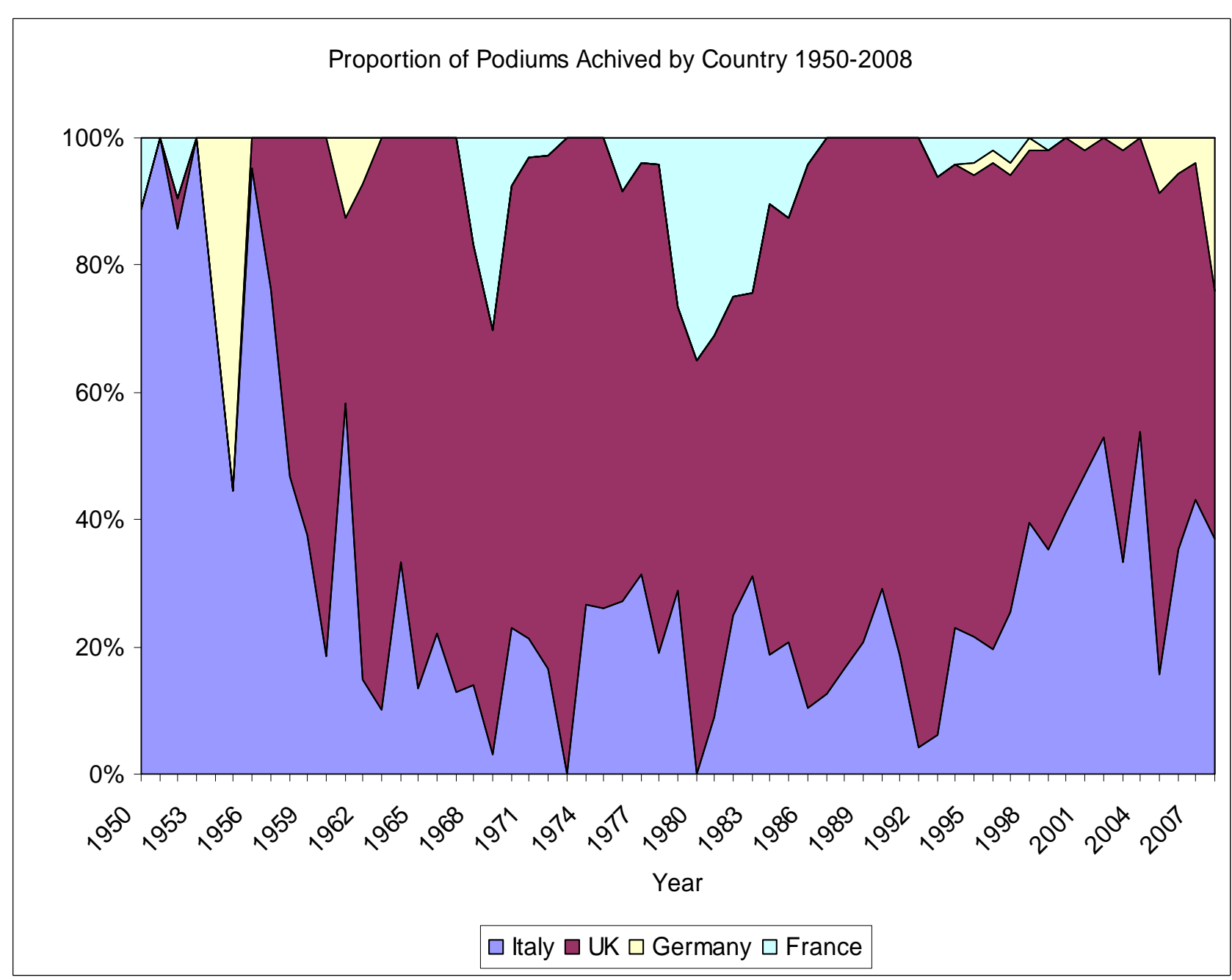

